\title{
DESOBSTRUÇÃO DE EMISSORES COM ÁCIDO FOSFÓRICO EM FERTIRRIGAÇÃO COM CLORETO DE POTÁSSIO VERMELHO
}

\author{
Floriano Luiz Suszek* \\ Marcio Antonio Vilas Boas** \\ Silvio Cesar Sampaio**** \\ Carlos Roberto Juchen **** \\ Vera Lucia Antunes de Lima******
}

RESUMO: Estudos na área da irrigação têm sido realizados com o objetivo de se racionalizar a utilização da água na agricultura. Um dos problemas mais comum nos sistemas de irrigação por gotejadores é o entupimento de emissores. Desta forma, o objetivo deste trabalho foi utilizar o ácido fosfórico como agente de limpeza de tubos gotejadores sob fertirrigação com cloreto de potássio vermelho. Assim este estudo utilizou um sistema de quimigação de tubos gotejadores conduzidos por gravidade, porém mantendo-se a pressão de entrada com baixa variação, em quatro tratamentos experimentais: irrigação antes da quimigação (T1); fertirrigação com cloreto de potássio vermelho (T2); quimigação com ácido fosfórico (T3); e irrigação depois da quimigação (T4), com seis repetições e tempo médio de uma hora por repetição. Os tratamentos que fertirrigaram soluções em uma concentração de $\mathrm{KCl}$ com $60 \%$ de potássio foram desobstruídos com ácido fosfórico em uma concentração de $7,086 \mathrm{~g} \mathrm{~L}^{-1}$, sendo esta operação analisada por coeficientes de uniformidade, gráficos de controle estatístico e mapas de contorno. Observou-se que no manejo de não abrir os finais de linha, os resíduos provenientes da desobstrução causaram um grau de entupimento de 15,13\% em média nas linhas dos tubos gotejadores. Os resultados mostraram que o ácido fosfórico pode ser utilizado como agente de limpeza em tubos gotejadores, porém requer manejo adequado do sistema.

PALAVRAS-CHAVE: Cartas de controle; Entupimento de gotejadores; Quimigação; Uniformidade de distribuição.

\footnotetext{
*Doutor em Engenharia Agrícola Universidade Estadual do Oeste do Paraná (UNIOESTE), Brasil.

** Doutor em Agronomia. Universidade Estadual do Oeste do Paraná (UNIOESTE), Brasil.

**** Docente Associado C na Universidade Estadual do Oeste do Paraná (UNIOESTE), Brasil.

***** Doutor em Engenharia Agrícola, Docente titular da Universidade Tecnológica Federal do Paraná (UTFPR), Brasil.

******* Docente Titular da Universidade Federal de Campina Grande (UFCG/PB), Brasil.
} 


\title{
DE-OBSTRUCTION OF DRIP EMITTERS WITH PHOSPHORIC ACID IN FERTIRRIGATION WITH RED POTASSIUM CHLORIDE
}

\begin{abstract}
Studies on irrigation have been undertaken to rationalize the use of water in agriculture. Clogging of drip emitters is one of the most common problems in irrigation. Phosphoric acid was employed as a cleaning agent of drips with red potassium chloride used for fertirrigation. Current assay employed a chemical irrigation system for gravity drips with entrance pressure at low variation, in four experimental treatments: irrigation prior to the use of the chemical irrigation system (T1); fertirrigation with red potassium chloride (T2); chemical irrigation system with phosphoric acid (T3); irrigation posterior to chemical irrigation system (4), with six replications, and $1 \mathrm{~h}$ as mean time per replication. Treatments with fertirrigation solutions in a concentration of $\mathrm{KCl}$ with $60 \%$ potassium were de-obstructed with phosphoric acid at a concentration of $7.086 \mathrm{~g} \mathrm{~L}^{-1}$. Procedure was analyzed by uniformity coefficients, statistical control graphs and contour maps. Residues from de-obstruction caused a mean $15.13 \%$ clogging within drip rows. Results showed that phosphoric acid may be employed as a cleaning agent in drip tubes, although adequate management of the system should be undertaken.
\end{abstract}

KEY WORDS: Control charts; Drip clogging; Chemical irrigation system; Distribution uniformity.

\section{INTRODUÇÃO}

A disponibilidade de alimentos para nutrição humana está relacionada ao aumento da produção, deste modo é indispensável a procura por mais espaço para plantio, contudo, preservando os recursos naturais. Outra opção é o uso da irrigação, a qual ocupa aproximadamente $6,5 \%$ da área total cultivada no planeta (FAOSTAT, 2013), e possibilita o aumento da produção alimentar em até 2,7 vezes, quando comparado à agricultura tradicional (CHRISTOFIDIS, 2013).

Porém, sistemas de irrigação requerem uma alta demanda de água, a qual deve ser utilizada da forma mais eficiente possível para evitar perdas (COELHO et al., 2005). Devido a este fato, várias leis de proteção aos recursos hídricos foram criadas, e estas são rigorosamente exigidas quando se faz um projeto de irrigação em uma área considerável. 
O Brasil possui um alto potencial para expansão das agriculturas irrigadas, porém são necessários estudos para que o uso dessa água seja mais eficiente, ou seja, que se evitem perdas do recurso, e também que sejam divulgadas mais informações para os agricultores sobre o manejo adequado dos sistemas de irrigação.

A agricultura irrigada precisa ser mais eficiente para manter-se sustentável, e tal eficiência pode ser alcançada atuando na estrutura e tipo de irrigação, em tipos de cultivos, na gestão de uso da água e no manejo da irrigação. Se utilizada de forma racional, a irrigação pode promover economia de água e energia. De acordo com a Agência Nacional de Águas (ANA, 2012), a agricultura irrigada é o principal uso consuntivo de água no país, e necessita de maior atenção para o uso racional deste recurso.

A irrigação localizada é o tipo mais eficiente de irrigação, pois aplica a água em forma de gota, diretamente no sistema radicular da planta, deixando o solo sempre próximo a capacidade de campo e reduzindo perdas por evaporação (COELHO et al., 2005). Segundo Sousa et al. (2011), o gotejamento apresenta as vantagens de economia de água e energia além de possibilitar automação e fertirrigação.

A fertirrigação é uma das maneiras mais eficientes e econômicas de aplicar-se fertilizante às plantas, quando há a necessidade de irrigação para o cultivo das mesmas (BASSO et al., 2010), sendo que na irrigação localizada, o processo de fertirrigação tende a ser facilitado.

Em um projeto de irrigação localizada, é muito importante fazer-se a análise da água que será utilizada, pois nela podem conter elementos que causem entupimento nos emissores, reduzindo a vazão e eficiência do sistema (CAPRA; SCICOLO$\mathrm{NE}, 1998$ ). Assim, podem ser utilizados produtos químicos para a limpeza das tubulações e emissores a base de ácidos ou que contenham cloro em sua composição.

As substâncias químicas dissolvidas na água de irrigação como, por exemplo, o carbonato de cálcio e o sulfeto de cálcio em altas concentrações, podem precipitar e eventualmente formar incrustações nas paredes das tubulações e emissores, restringindo a passagem da água. Problemas com incrustações e corrosão das tubulações são frequentes quando se utilizam águas subterrâneas (RIBEIRO et al., 2005), onde a presença de Ferro $(\mathrm{Fe})$ é mais comum, aumentando a perda de carga no sistema de irrigação (MOURA et al., 2011) e favorecendo a obstrução de emissores 
(SANTOS; HERNANDEZ, 2013).

O manejo do sistema com uso de filtros e cloração são recomendados a fim de prevenir ou desobstruir emissores parcial ou totalmente entupidos (RESENDE et al., 2000). Busato et al. (2012) utilizaram cloração com dicloroisocianurato de sódio como prevenção ao entupimento de emissores, apresentando resultados satisfatórios em irrigação com águas ferruginosas.

A uniformidade de distribuição de um sistema de irrigação vem a ser a disponibilidade da água irrigada nos emissores de forma mais igualitária possível para as plantas, sem risco de irrigação excessiva em algumas áreas enquanto outras não atingiram sua necessidade hídrica (MANTOVANI et al., 2009). O acompanhamento da uniformidade pode prevenir ou mostrar problemas na vazão do sistema.

Nesse contexto, este trabalho teve como objetivo utilizar o ácido fosfórico como agente de limpeza de tubos gotejadores em processos de fertirrigação com cloreto de potássio vermelho.

\section{MATERIAL E MÉTODOS}

O experimento foi realizado em uma propriedade rural na região Sudoeste do Estado do Paraná, onde há cultivo de videiras. No local havia um sistema de irrigação por gotejamento com tubos STREAMLINE ${ }^{\mathrm{TM}} 16060$ (NETAFIM), com três anos de uso, com vazão nominal de 1,6 $\mathrm{Lh}^{-1}$, e pressão de serviço de $350 \mathrm{kPa}$.

O sistema foi conduzido por gravidade, composto por filtro de tela, sendo montado um aplicador de produtos químicos próximo ao reservatório de água, para que fosse feita a mistura dos produtos antes da aplicação a campo. O croqui do sistema de irrigação instalado na área experimental pode ser visualizado na Figura 1. 


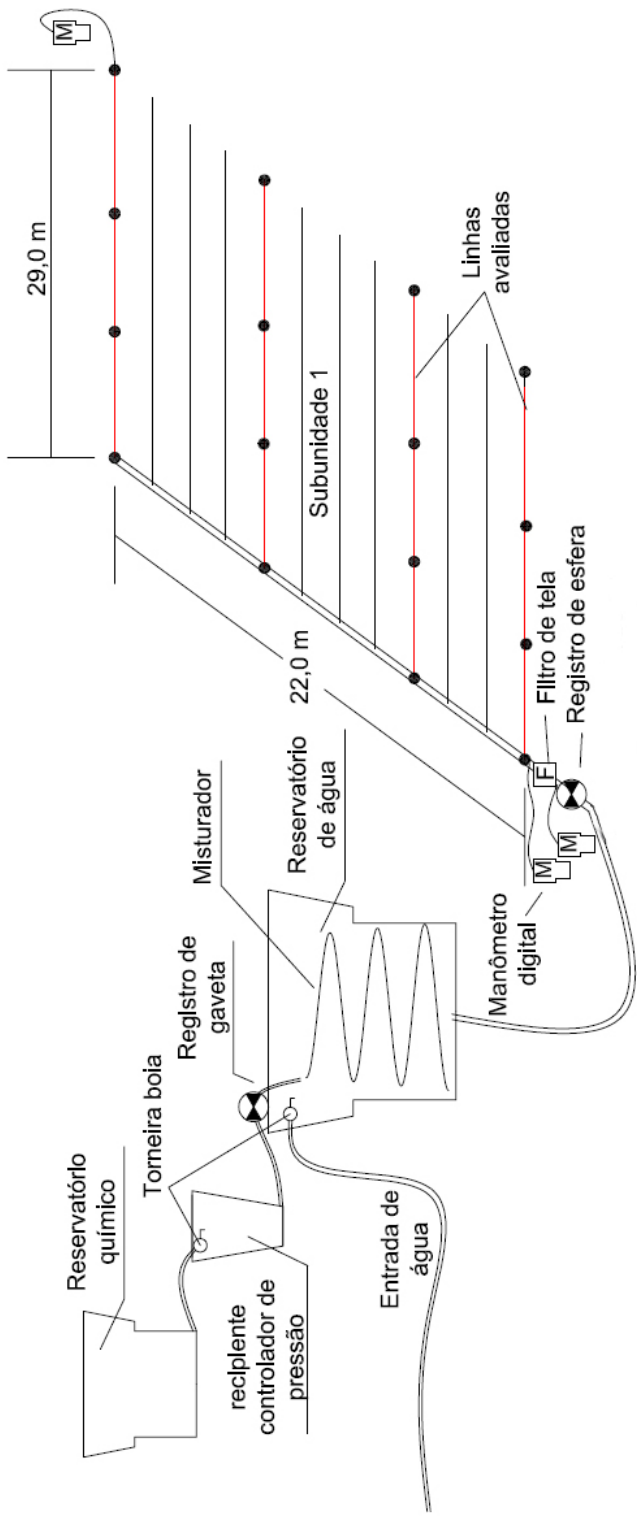

Figura 1. Visualização do croqui do sistema de irrigação instalado na área experimental.

Os tratamentos utilizados foram: irrigação antes da quimigação (T1); fertirrigação com cloreto de potássio vermelho (T2); quimigação com ácido fosfórico (T3); e irrigação depois da quimigação (T4), com seis repetições e tempo médio de 
uma hora por repetição.

O sistema operou por meio de um recipiente que continha uma torneira boia, e localizado entre os reservatórios de água e produto químico, sendo que o fertilizante utilizado permanecia no recipiente em nível constante, sendo liberado para o reservatório de água de irrigação por meio de um registro de gaveta, o qual controlava a vazão do produto.

A mistura dos produtos químicos à água de irrigação foi feita no próprio reservatório de água com auxílio de um misturador composto por uma mangueira em espiral com furos ao longo de sua extensão. A distribuição da calda no sistema foi direcionada por registro de esfera, e o monitoramento da pressão foi feito por manômetros digitais, instalados antes e depois do filtro na parte inicial do sistema $\mathrm{e}$ outro no final do sistema de irrigação.

A fertirrigação foi realizada com uma solução de cloreto de potássio $(\mathrm{KCl})$, em concentração de $60 \%$ de potássio, com seis horas de duração total, sendo estrategicamente preparada em um reservatório químico acima do nível do reservatório de água de irrigação, com torneiras boia para manter a pressão e vazão de entrada da solução no reservatório de água, com baixa variação.

O total aplicado foi de $21,26 \mathrm{~kg}$ de cloreto de potássio, calculado com base na análise de solo da área, seguindo recomendações de Embrapa (2011) para cultivo de videiras. O processo de limpeza do sistema foi feito com ácido fosfórico $\left(\mathrm{H}_{3} \mathrm{PO}_{4}\right)$, o qual também apresenta a função de fertilizante, sendo utilizado 10,63 kg de ácido fosfórico para cada 1500 litros de água, resultando na concentração de 7,086 $\mathrm{g} \mathrm{L}^{-1}$.

Utilizou-se a metodologia de coleta de dados segundo Keller e Karmeli (1975), na qual são selecionadas, para amostragem, as linhas laterais correspondentes a primeira, a última, $1 / 3$ e $2 / 3$ do número de linhas laterais, sendo coletadas as vazões nos primeiros, últimos, $1 / 3$ e $2 / 3$ do número de gotejadores das quatro linhas selecionadas, totalizando 16 gotejadores avaliados.

As avaliações ocorreram com uso de coletores abaixo dos gotejadores com baixa variação de pressão, com quatro minutos em cada coleta, resultando em vazões amostrais. A pressão foi mensurada por manômetros digitais e a vazão medida por provetas graduadas.

Com os dados de vazão obtidos foi possível calcular o CUD (Coeficiente de 
Uniformidade de Distribuição), proposto por Criddle et al. (1956), e o CV (Coeficiente de Variação de Vazão no Campo), adaptado do coeficiente de variação estatístico. De posse dos dados foi possível ainda analisar o entupimento ao longo do tempo pela variação dessa uniformidade com uso da irrigação e fertirrigação, devido às variações de vazão no sistema.

Com as vazões (inicial e final) dos tratamentos, calculou-se o grau de entupimento, verificando assim a influência do entupimento da descarga dos emissores. O cálculo do grau de entupimento foi realizado conforme a Equação 1.

$$
\mathrm{GE}=\left(1-\frac{\mathrm{q}_{\text {atual }}}{\mathrm{q}_{\text {novo }}}\right) 100
$$

Em que: GE - é o Grau de Entupimento, \%; $q_{\text {atual - }}$ é a vazão depois da fertirrigação, $L^{-1}$; e $q_{\text {novo }}$ - é a vazão antes da fertirrigação, $L^{-1}$.

Para o monitoramento dos dados, foram utilizados gráficos de controle estatístico de medidas individuais da vazão, CUD e CV, os quais podem apresentar pontos onde o processo sai do controle devido a problemas de causas específicas ou especiais, sendo que os limites de controle são determinados por três desvios padrões a partir da média (MONTGOMERY, 2009) e convencionados pelo software MINITAB 16. De acordo com Montgomery (2009), a média e o desvio padrão devem ser estimados a partir de amostras preliminares ou subgrupos, quando se espera controle no processo. Estas estimativas devem ser baseadas em pelo menos 20 a 25 amostras.

Os limites de especificação utilizados nos gráficos de controle foram baseados nos coeficientes de uniformidade (CUD e CV), sendo os valores de classificação dos coeficientes os descritos da literatura pela ASABE (2008). Para o gráfico de controle da vazão foram utilizados os limites de controle com $3 \sigma$, ou seja, três vezes o desvio padrão dos dados amostrais. 


\section{RESULTADOS E DISCUSSÃO}

A análise da água, utilizada na irrigação, foi realizada pelo Laboratório de Saneamento Ambiental do Departamento de Recursos Hídricos e Saneamento Ambiental da Universidade Estadual do Oeste do Paraná (UNIOESTE), e os resultados dos parâmetros analisados são apresentados na Tabela 1 , com seus respectivos riscos de entupimento ao sistema gotejador.

Tabela 1. Parâmetros físico-químicos da água e classificação do risco de entupimento de emissores

\begin{tabular}{lccc}
\hline \multirow{2}{*}{ Parâmetros } & Amostra de água & Fator de risco & \\
\cline { 2 - 4 } & & $\mathrm{A}$ & $\mathrm{B}$ \\
Sólidos suspensos $\left(\mathrm{mg} \mathrm{L}^{-1}\right)$ & 12,0 & baixo & baixo \\
Condutividade elétrica $\left(\mathrm{dS} \mathrm{m}^{-1}\right)$ & 0,122 & baixo & baixo \\
$\mathrm{pH}$ & 6,75 & n.c. & baixo \\
Ferro $\left(\mathrm{mg} \mathrm{L}^{-1}\right)$ & 124,0 & alto & alto \\
Manganês $\left(\mathrm{mg} \mathrm{L}^{-1}\right)$ & 12,0 & alto & alto \\
Cálcio (mg L-1 & 68,0 & baixo & n.c. \\
Magnésio $\left(\mathrm{mg} \mathrm{L}^{-1}\right)$ & 133,0 & alto & n.c. \\
\hline
\end{tabular}

(A) Classificação segundo Capra e Scicolone (1998); (B) Classificação segundo Nakayama e Bucks (1986); n.c. = não classificado.

A amostra de água era provinda de fonte subterrânea, em que a concentração de ferro foi alta devido à composição do solo. Barboza et al. (2011) afirmam que o ferro pode comprometer a eficiência de sistemas de irrigação, principalmente quando se trata de gotejamento.

$\mathrm{Na}$ Tabela 2 são apresentadas as médias das vazões em cada tratamento considerado. Os tratamentos T1 e T2 apresentaram estatisticamente igualdades significativas entre si, diferindo dos tratamentos T3 e T4, estatisticamente iguais entre si, o que implica dizer que a aplicação de ácido fosfórico influenciou no desprendimento de partículas aderidas internamente na tubulação, que se direcionaram para os gotejadores, reduzindo assim a vazão em T4. 
Tabela 2. Vazões médias dos tratamentos

Tratamento

Irrigação antes da quimigação (T1)

Fertirrigação com cloreto de potássio vermelho (T2)

Quimigação com ácido fosfórico (T3)

Irrigação depois da quimigação (T4)
Vazão $\left(\mathrm{L} \mathrm{h}^{-1}\right)^{*}$

0,489 a

$0,490 \mathrm{a}$

$0,441 \mathrm{~b}$

$0,414 \mathrm{~b}$

*Letras iguais correspondem a médias estatisticamente iguais a 0,05 de significância pelo teste de Tukey.

$\mathrm{Na}$ Figura 2A, observa-se o controle da vazão ao longo dos tratamentos. Verifica-se que alguns pontos saíram de controle estatístico, quando utilizados os limites de controle de três desvios padrões da média preconizados pelo software MINITAB 16, sendo que os pontos acima do limite superior de controle (LSC) apresentaram baixa variação. Porém os pontos abaixo da linha inferior de controle (LIC) indicam deficiência do sistema, sendo reduzida a partir da avaliação 11 e seguindo tendência negativa até o final das avaliações.

O entupimento começa a ser causado pelo fertilizante na avaliação 11 e se torna mais grave durante a aplicação do ácido fosfórico, que desprende o material preso à tubulação e deposita estes sedimentos nos gotejadores posteriores, fazendo com que o tratamento T4 (irrigação somente com água) apresente uma vazão reduzida em relação à vazão inicial.

Analisando a pressão inicial do sistema ao longo dos tratamentos (Figura 2B), esta se manteve com pouca variação nas primeiras e últimas avaliações, com média geral de $7,95 \mathrm{kPa}$, mostrando que a redução de vazão foi causada pelo entupimento dos emissores. Os pontos 18 e 19 apresentaram maiores picos de pressão porque os emissores apresentavam entupimento devido à sedimentação do fertilizante, e ocasionado pela ação do ácido fosfórico que a princípio tem uma ação eficaz na remoção das incrustações. Porém a falta de sua remoção ocasiona outras obstruções adiante na linha de gotejamento, que aumenta a pressão no sistema.

Na Figura 2C, observa-se que os valores de CUD, que é sensível a alterações de vazão no sistema, e por ser mais rígido em trabalhar com as mínimas vazões que foram coletadas, apresentaram variação alta. A classificação do CUD se manteve boa (75 a 90\%) nos três primeiros tratamentos e classificada como ruim (50 a 62\%) em 
T4. O entupimento causado pelo desprendimento do fertilizante das tubulações causou a redução da vazão, influenciando na uniformidade de distribuição. Para uma melhoria na uniformidade, Puig-Bargués et al. (2010) recomendam técnicas como sedimentação, filtração, aumento da pressão de serviço e limpeza das linhas laterais com água.
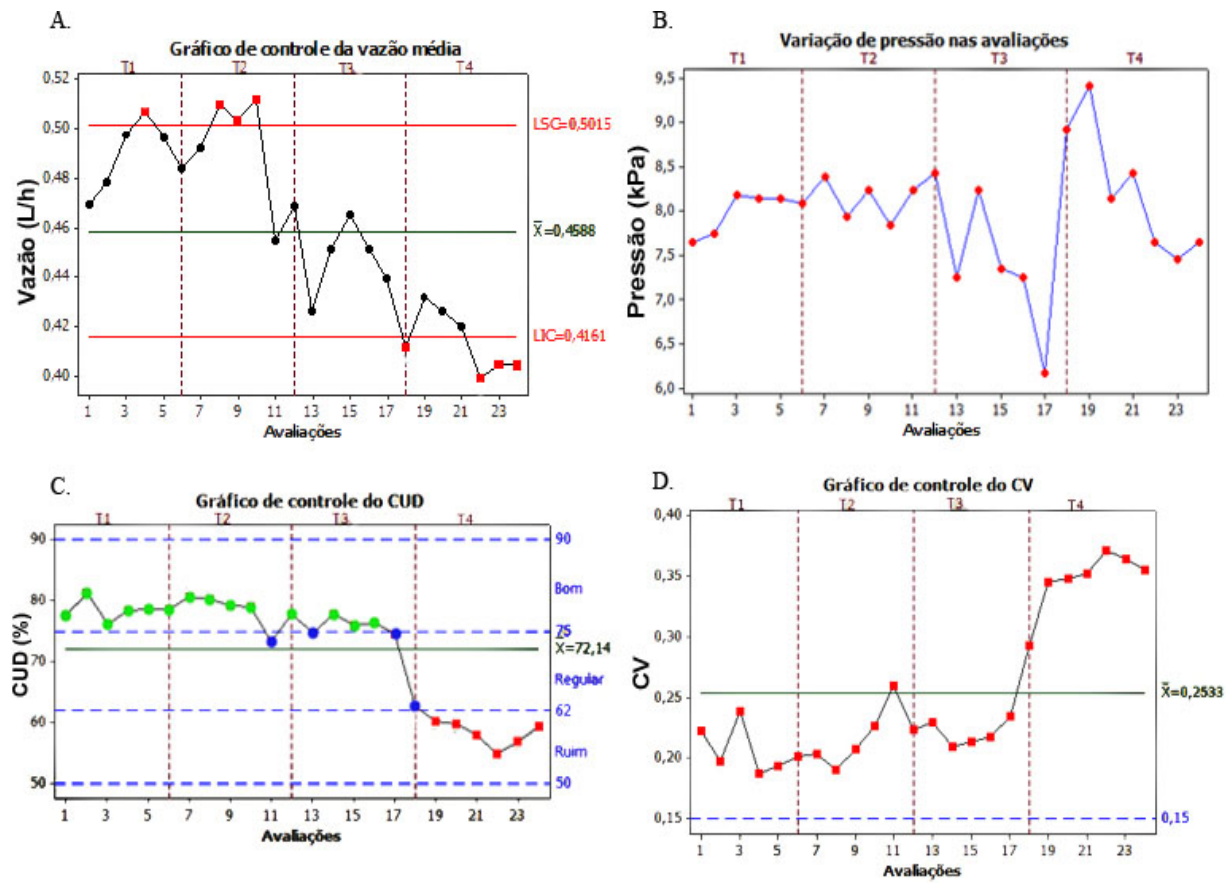

Figura 2. Controle da vazão no sistema (A), variação de pressão (B), controle do CUD (C), controle do CV (D) ao longo das avaliações experimentais.

$\mathrm{Na}$ Figura 2D são apresentados os valores do coeficiente de variação (CV), que é mais rigoroso quanto a sua classificação, assim, todas as avaliações foram classificadas como inaceitáveis (abaixo de 0,15), apresentando comportamento semelhante ao CUD, com maior variação no tratamento T4, pois alguns gotejadores avaliados estavam parcialmente entupidos e um completamente entupido, e deste modo a variação da vazão dos tubos gotejadores e, consequentemente, do sistema de irrigação foi extremamente prejudicada, o que influenciou muito na variação de 
vazão do sistema. Hermes et al. (2013) também encontraram alta variabilidade do CV quando aplicada fertirrigação no sistema de irrigação localizada.

Deus et al. (2011) utilizaram ácido fosfórico na fertirrigação e não obtiveram entupimento de gotejadores, nem acidificação do solo no bulbo molhado. Porém, um fato deve ser observado, os finais de linha não foram abertos para a saída dos resíduos do fertilizante, propositalmente, logo as obstruções nos tubos gotejadores foram facilitadas, para em seguida avaliar a capacidade de desobstrução dos emissores com o uso do ácido fosfórico, com um pH médio de 2,56. Assim também foi possível observar um resultado de uma segunda causa da obstrução dos emissores pelo desprendimento das partículas de cloreto de potássio ocorrido pela ação do ácido fosfórico.

Segundo Camargo (2010) o cloreto de potássio vermelho, apesar de ser a fonte de potássio mais barata, não é uma opção aconselhada para a fertirrigação por apresentar baixa solubilidade, podendo causar entupimento de emissores.

Durante as avaliações do tratamento T2, observou-se pH médio de 8,23 e condutividade elétrica média nos tratamentos T2 e T3 de 2,12 dS m e 2,83 dS m-1, respectivamente. De acordo com os valores apresentados por Nakayama e Bucks (1986), o risco de entupimento aos emissores é severo se o $\mathrm{pH}$ for maior que 8,0 e moderado se a condutividade elétrica for de 0,70 a 3,00 dS m-1.

Juchen et al. (2013) utilizaram um processo de diluição em água de efluentes agroindustriais em sistemas de fertirrigação de alface por meio de gotejamento e, assim, obtiveram menores valores da concentração de sólidos totais dissolvidos, que consequentemente diminuíram os riscos de entupimento do sistema de irrigação.

A presença do ferro na água de irrigação, em alta concentração, também contribui para o entupimento dos emissores, quando aplicado o fertilizante cloreto de potássio vermelho, como é apresentado por Ribeiro et al. (2010), avaliando desempenho de gotejadores com uso deste fertilizante. Como em águas subterrâneas de Latossolos, na região Sudoeste do Paraná, é elevada a concentração de ferro, não se recomenda fazer uso de cloreto de potássio na fertirrigação. 
O grau de entupimento calculado para as vazões médias referentes aos tratamentos T1 e T3, sendo analisadas as vazões antes e depois da fertirrigação, foi de 9,81\%, e para os tratamentos T1 e T4, referentes a vazão inicial e a vazão depois da aplicação do ácido fosfórico, apresentou resultado de 15,13\%.

Para uma melhor observação do grau de entupimento, a Figura 3 apresenta a vazão média dos gotejadores avaliados, em cada tratamento, na forma de mapas de contorno interpolados pelo método do inverso do quadrado da distância, onde cores mais escuras representam menores vazões.

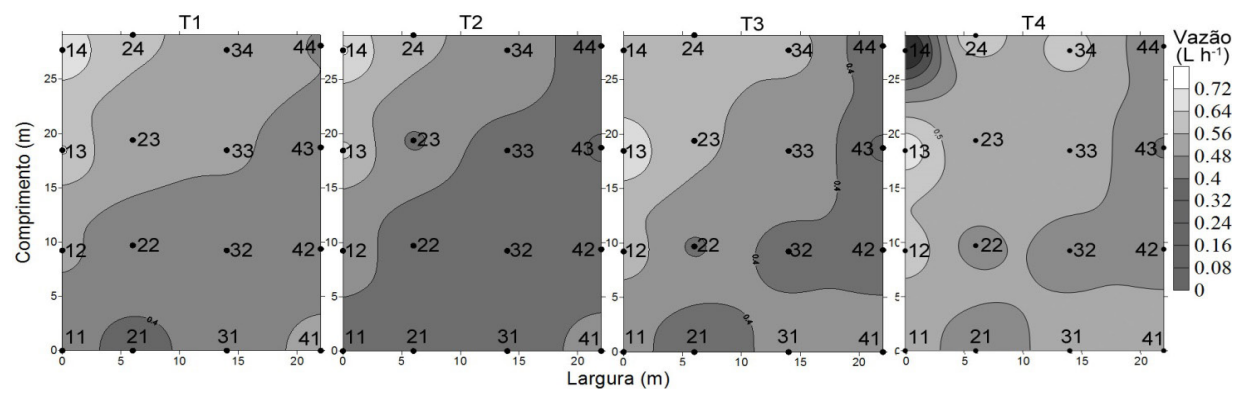

Figura 3. Mapas de contorno da vazão média para cada tratamento.

Para os gotejadores 11, 12, 13 e 21, a vazão apresentou aumento após o tratamento de desobstrução (T4), sendo até maior que a vazão em T1. O gotejador 14 apresentou entupimento total do emissor $(\mathrm{GE}=100 \%) \mathrm{e}$, os outros emissores, entupimento parcial com GE correspondendo a 16, 30 e 28\% para os emissores 42 , 43 e 44 , respectivamente.

Uma classificação para o GE, feita por Morata et al. (2014), mostra que o grau de entupimento entre T1 e T3 foi baixo, e para T1 e T4 foi médio. Para Ribeiro et al. (2012), manter a elevada uniformidade do sistema é fundamental para a eficiência no aproveitamento dos recursos hídricos.

O mapa de vazões para T4 apresenta aumento nos valores de vazão, que ocorre devido ao sistema ser não-autocompensante, assim, com um emissor obstruído (emissor 14), a pressão no sistema será redistribuída entre os outros gotejadores, aumentando a vazão dos mesmos.

$\mathrm{Na}$ utilização de ácido nítrico para desobstrução de emissores em fertirrigação de superfosfato simples em que também os emissores foram induzidos ao entu- 
pimento, Barros et al. (2009) obtiveram efeito contrário, obstruindo os emissores, efeito que é verificado também neste trabalho.

Dessa forma, observa-se que o aumento do grau de entupimento pode também ser promovido pelo agente de limpeza utilizado nas tubulações gotejadoras, pois constatou-se que o uso do ácido fosfórico, que realiza a ação de limpeza nas tubulações e remoção de incrustações, pode contribuir para a obstrução de outros emissores devido ao material desprendido, principalmente quando os finais de linha não são abertos para limpeza correta do sistema de irrigação.

\section{CONSIDERAÇÕES FINAIS}

A quimigação diluída de ácido fosfórico, sem abertura dos finais de linha, aumentou o grau de entupimento em média de $15,13 \%$, porém com a ação de limpeza em alguns emissores.

O uso de cloreto de potássio vermelho como fertilizante, na irrigação por gotejamento, apresenta risco elevado de entupimento quando utilizado em alta concentração e na presença de águas ferruginosas.

Os sedimentos liberados pela ação do ácido fosfórico bloqueiam a emissão de água dos gotejadores adjacentes.

\section{REFERÊNCIAS}

AGÊNCIA NACIONAL DE ÁGUAS. Conjuntura dos recursos hídricos no Brasil: informe 2012. Ed. Especial. 215 p. Brasília: ANA, 2012.

AMERICAN SOCIETY OF AGRICULTURAL AND BIOLOGICAL ENGINEERS - ASABE. Design and installation of microirrigation systems. St. Joseph, 6 p. 2008.

BARBOZA, G. C.; HERNANDEZ, F. B. T.; FRANCO, R. A. M. Análise de riscos à sistemas de irrigação causados pela qualidade da água do córrego do Coqueiro - SP. Revista Brasileira de Agricultura Irrigada, v. 5, n. 1, p. 24-36, 2011.

BARROS, A. C.; COELHO, R. D.; MEDEIROS, P. R. F.; MELO, R. F.; BARBOSA JÚNIOR, 
C. R. A.; DIAS, C. T. S. Entupimento de gotejadores em função da aplicação de superfosfato simples e ácido nítrico. Revista de Engenharia Agrícola, v. 29, p. 62-71, 2009.

BASSO, L. H.; BRAGA, M. B.; CALGARO, M.; SIMÕES, W. L.; PINTO, J. M. Cultivo da videira. Sistemas de produção 1-2. ed. Versão eletrônica: Embrapa Semiárido. 2010.

BUSATO, C. C. M.; SOARES, A. A.; RAMOS, M. M.; REIS, E. F.; BUSATO, C. Dicloroisocianurato na prevenção do entupimento devido ao uso de águas ferruginosas em sistemas de irrigação por gotejamento. Revista Semina: Ciências Agrárias, Londrina, v. 33, n. 1, p. 49-56, 2012.

CAMARGO, D. C. Uniformidade de distribuição de potássio utilizando diferentes fontes e concentrações na calda de fertirrigação em condições de campo. 2010. 66 f. Dissertação (Mestrado em Engenharia Agrícola) - Universidade Federal do Ceará, Fortaleza, 2010.

CAPRA, A.; SCICOLONE, B. Water quality and distribution uniformity in drip/trickle irrigation systems. Journal of Agricultural Engineering Research, v. 70, p. 355365, 1998.

CHRISTOFIDIS, D. Água, irrigação e agropecuária sustentável. Revista de Política Agrícola, Brasília, v. 22, n. 1, p. 115-127, 2013.

COELHO, E. F.; COELHO FILHO, M. A.; OLIVEIRA, S. L. Agricultura irrigada: eficiência de irrigação e de uso de água. Revista Bahia Agrícola, v. 7, n. 1, p. 57-60, 2005.

CRIDDLE, W. D.; DAVIS, S.; PAIR, C. H.; SHOCKLEY, D. G. Methods for evaluating irrigation systems. Washington: Soil Conservation Service, Agricultural Handbook, n. 82, 24p, 1956.

DEUS, A. C. F.; COSTA, C. D. O.; FORATTO, L. C.; FERNANDES, D. M.; CARRIBEIRO, L. S. Alface americana fertirrigada com diferentes doses de potássio. Irriga, Botucatu, v. 16, n. 2, p. 125-133, 2011.

EMBRAPA - Empresa Brasileira de Pesquisa Agropecuária. Furticultura irrigada. Brasília: EMBRAPA, 274p, 2011.

FAOSTAT. Production, Crop, Area harvested, 2013. Disponível em: http://faostat. 
fao.org. Acesso em: fev. 2015.

HERMES, E.; VILAS BOAS, M. A.; GOMES, S. D.; GOMES, B. M.; REIS, C. F. Quality control in irrigation and fertigation with cassava processing wastewater into drip system. Journal of Food, Agriculture \& Enviroment, v. 11, p. 841-845, 2013.

JUCHEN, C. R.; SUSZEK, F. L.; VILAS BOAS, M. A. Irrigação por gotejamento para produção de alface fertirrigada com águas residuárias agroindustriais. Revista Irriga, v. 18, p. 243-256, 2013.

KELLER, J.; KARMELI, D. Trickle irrigation design. Rain Bird Sprinkler Manufacturing Corporation, 1975. $133 \mathrm{p}$.

MANTOVANI, E. C.; FACCIOLI, G. G.; LEAL, B. G.; SOARES, A. A.; COSTA, L. C.; FREITAS, P. S. L. Influence of the water distribution uniformity and irrigation depth on the yield of irrigated bean crop. Irriga, Botucatu, v. 14, n. 4, p. 458-469, 2009.

MONTGOMERY, D. C. Introduction to statistical quality control. $6^{a}$ ed. Tempe: John Wiley \& Sons, Inc. 734p, 2009.

MORATA, G. T.; DANTAS, G. F.; DALRI, A. B.; PALARETTI, L. F.; FARIA, R. T.; SANTOS, G. O. Entupimento de gotejadores com uso de efluente de esgoto sob dois sistemas de filtragem. Revista Brasileira de Agricultura Irrigada, v. 8, n. 2, p. 86-97, Fortaleza, 2014.

MOURA, R. da S.; HERNANDEZ, F. B. T.; LEITE, M. A.; FRANCO, R. Qualidade da água para uso em irrigação na microbacia do Córrego do Cinturão Verde, município de Ilha Solteira/SP. Revista Brasileira de Agricultura Irrigada, Fortaleza, v. 5, n. 1, p. 8-74, 2011.

NAKAYAMA, F. S.; BUCKS, D. A. Trickle irrigation for crop production: design, operation and management. Amsterdam: Elsevier, 1986. 164p.

PUIG-BARGUÉS, J.; ARBAT, G.; ELBANA, M.; DURAN-ROS, M.; BARRAGÁN, J.; CARTAGENA, F. R. de; LAMM, F. R. Effect of flushing frequency on emitter clogging in microirrigation with effluents. Agricultural Water Management, v. 97, p. 883-891, 2010.

RESENDE, R. S.; COELHO, R. D.; PIEDADE, S. M. S. Eficiência da cloração da água 
de irrigação no tratamento de gotejadores com entupimento de causa biológica. Revista Brasileira de Engenharia Agrícola e Ambiental, v. 4, n. 3, p. 382-389, 2000.

RIBEIRO, P. A. A.; COELHO, R. D.; TEIXEIRA, M. B.; Entupimento de tubos gotejadores convencionais com aplicação de cloreto de potássio (vermelho e branco) via duas qualidades de água. Revista de Engenharia Agrícola, v. 30, p. 279-287, 2010.

RIBEIRO, P. A. de A.; TEIXEIRA, M. B.; COELHO, R. D.; FRANCO, E. M.; SILVA, N. F. da; CARVALHO, L. C. C. de; ALVES, M. E. B. Gotejadores submetidos a condições críticas de qualidade da água. Brazilian Journal of Irrigation and Drainage - IRRIGA, Botucatu, Ed. Especial, p. 368-379, 2012.

RIBEIRO, T. A. P.; AIROLDI, R. P. S.; PATERNIANI, J. E. S.; SILVA, M. J. M. Variação dos parâmetros físicos, químicos e biológicos da água em um sistema de irrigação localizada. Revista Brasileira de Engenharia Agrícola e Ambiental, v. 9, p. 295301, 2005.

SANTOS, G. O.; HERNANDEZ, F. B. T. Uso do solo e monitoramento dos recursos hídricos no córrego do Ipê, Ilha Solteira, SP. Revista Brasileira de Engenharia Agrícola e Ambiental, Campina Grande, v. 17, n. 1, p. 60-68, 2013.

SOUSA, V. F. de; MAROUELLI, W. A.; COELHO, E. F.; PINTO, J. M.; COELHO FILHO, M. A. Irrigação e fertirrigação em fruteiras e hortaliças. Embrapa: Informação Tecnológica, Brasília, 771p, 2011.

Recebido em: 07/06/2017

Aceito em: 24/05/2018 